\title{
Call for Special Focus Issue Papers: Integrative Palliative Care
}

\section{Deadline for Manuscript Submission: January 31, 2020}

\author{
Guest Editors: Shelley Adler, PhD and Delia Chiaramonte, MD
}

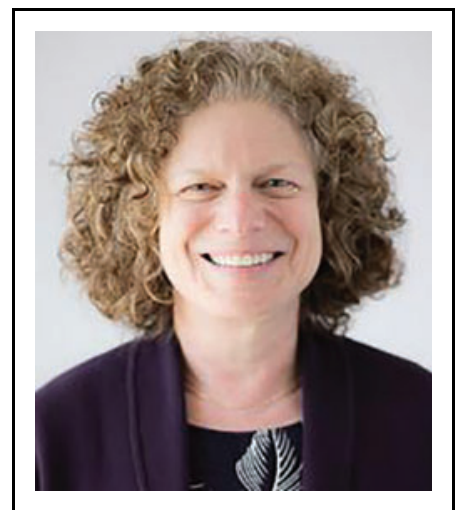

Shelley Adler, PhD Director, Osher Center for Integrative Medicine, UCSF Osher Foundation Distinguished Professor of Integrative Medicine Professor, Department of Family and Community Medicine

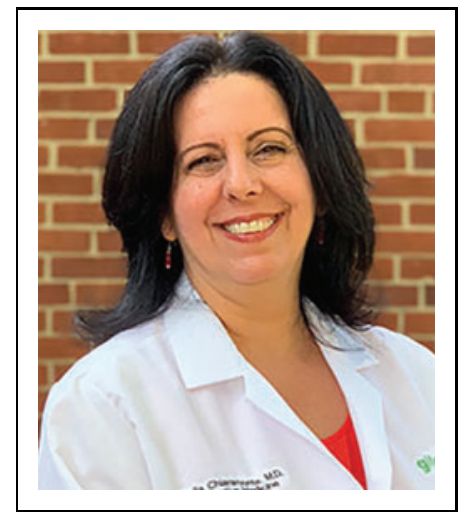

Delia Chiaramonte, MD Division Chief, Integrative \& Palliative Care, Gilchrist, Greater Baltimore Medical Center

Special Issue Advisory Team:

Jennifer Moore Ballentine, MA

Executive Director

CSU Shiley Institute for Palliative Care

Stephanie Cheng, MD

Assistant Professor of Clinical Medicine, Division of Palliative Medicine, UCSF

Department of Medicine

Danielle Josette Doberman, MD, MPH

Course Director, Palliative Care and Pain

Clinical Elective

Assistant Professor of Medicine, Johns

Hopkins Medicine

Scott A. Irwin, MD, PhD

Director, Supportive Care Services, Cedars-Sinai

Samuel Oschin Comprehensive Cancer Institute
Brieze Robinson Keeley, MD

Integrative Palliative Care Physician, UCSF Osher Center for Integrative Medicine Instructor, UCSF Division of Palliative Care

Gabriel Lopez, MD

Medical Director of the Integrative Medicine Center, MD Anderson Cancer Center, Department of Palliative, Rehabilitation, \& Integrative Medicine

Robin Majeski, PhD, RN

Clinical Associate Professor, The Erickson School, University of Maryland at Baltimore County

Mary Lynn McPherson, PharmD, MA, MDE, BCPS, CPE Professor, Executive Director, Advanced Post-Graduate Education in Palliative Care, University of Maryland School of Pharmacy 
The fields of Palliative Care and Integrative Health have both advanced substantially over the past two decades. These movements share many fundamental values-patient-centeredness, respecting the body-mind-spirit whole person continuum, and supportive and complementary roles, yet the fields have grown in parallel rather than intentionally examining their shared mission. In 2020, JACM: Paradigm, Practice and Policy Advancing Integrative Health (The Journal of Alternative and Complementary Medicine) will publish a Special Focus Issue on Integrative Palliative Care. The goal will be to enhance the natural synergy between integrative health and palliative medicine by drawing research and commentary that examine integrative palliative care. (For more reflection on the convergence, please see Adler et al. "Integrative Palliative Care: Enhancing the Natural Synergy Between Integrative Health and Palliative Medicine" JACM, March 2019).

Guiding the special issue are guest editors Shelley R. Adler, PhD and Delia Chiaramonte, MD. Adler is Director of the University of California, San Francisco Osher Center for Integrative Medicine. She is a researcher and

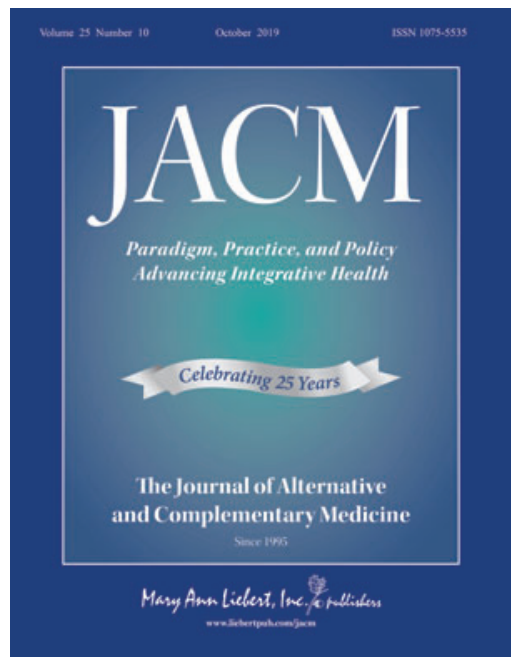
medical educator focusing on palliative and end-of-life care, with an emphasis on integrative health equity. Chiaramonte is an integrative palliative care clinician at Gilchrist/Greater Baltimore Medical Center and was previously an integrative educational leader with the University of Maryland School of Medicine where she was the Associate Director and Director of Education for the University of Maryland School of Medicine Center for Integrative Medicine. She teaches in the Palliative Care Master's Program at the University of Maryland School of Pharmacy. Drs. Adler and Chiaramonte are supported by a Special Issue Advisory Team.

We invite your submissions! We are seeking original research and reviews in these areas: integrative palliative methods, examinations of multimodal approaches, implementation-related studies including exploration of cost and business models issues, and education research. If you have ideas that you believe would be solid additions but are not explicitly called out here, please send us a query.

Manuscript submission due date: January 31, 2020. When submitting your paper, please select the "Special Issue on Integrative Palliative Care" manuscript category to ensure it is considered for this special issue. Original manuscripts should be no longer than 3,000 words, and Systematic Reviews should be no longer than 4,500 words. Title, abstract, acknowledgments, disclosures, references, and figure/table legends do not count toward the word limit.

Additional feature: As an additional feature in this JACM Special Focus Issue, we urge your submission of a 500word commentary to reflect on next steps for integrative palliative care: controversies; unusual experiences (not case reports); models of care; educational models; etc. We will select from those submitted a set that will be published together to capture the challenges and opportunities for this moment for the field.

If you have questions in this area, or ideas for other submissions that might strengthen the value of this special issue, please feel free to query us via Editor-in-Chief John Weeks at jweeks.jacm@gmail.com.

Submit your paper for peer review online: http://mc.manuscriptcentral.com/jaltcompmed 